JIOM Nepal, Volume 41, Number 2, August 2019, page 65-66

\title{
Thyroglossal Duct Fistula with an Unusual Presentation: A Case Report
}

\section{Bigyan R Gyawali, Heempali Dutta, Prashant Tripathi}

Department of Otorhinolaryngology and Head and Neck Surgery, Maharajgunj Medical Campus, Ganesh Man Singh Memorial Academy of ENT - Head \& Neck Studies, Tribhuvan University Teaching Hospital, Kathmandu, Nepal

\section{Corresponding author:}

Bigyan R Gyawali, MBBS, MS

Department of Otorhinolaryngology and Head and Neck Surgery, Maharajgunj Medical Campus, Tribhuvan University Teaching Hospital, Kathmandu

Email: bigyan.gyawali@gmail.com

Submitted : Apr 16, 2019

Accepted : June 27, 2019

\begin{abstract}
Thyroglossal duct anomaly is one of the commonest congenital anomalies with midline neck manifestation. Though commonest location mentioned in the literature is thyrohyoid, several rare presentations have also been described. Here, we present a very rare case of thyroglossal fistula manifesting in submental region.
\end{abstract}

Keywords: Fistula, submental, thyroglossal duct

\section{INTRODUCTION}

$$
\text { T }
$$

hyroglossal cyst or fistula is one of the commonest presentations as midline neck lesion in paediatric population. Being a developmental anomaly, site of presentation varies greatly with throhyoid being the most common location. ${ }^{1}$

Here we present a rare case of three year old boy presenting with a submental sinus which was later diagnosed as thyroglossal duct fistula on histological examination after surgical excision.

\section{CASE PRESENTATION}

A three years old boy presented to our OPD with his parents with complaint of intermittent discharge from the submental region for the past three months. The opening was preceded by a swelling one year back which spontaneously appeared and ruptured. The opening had persisted since then. The discharge from the opening was intermittent, mucoid and scanty in amount. It was often aggravated by upper respiratory tract infection. The child had no significant past medical and surgical history. Family history was not significant. There was no known exposure to patients with tuberculosis.

General examination was normal with no significant findings. Local examination of the neck revealed a single, small opening in the submental region in the midline, approximately $2.5 \mathrm{~cm}$ from the mentum. Sorrounding skin was normal with no features of inflammation. Margin of the sinus appeared normal. There were no obvious swellings or any other sinus openings in the neck. Palpation revealed no tenderness or induration in the sinus margin. Tract couldn't be palpated. Neck was normal on palpation with no neck nodes or swellings. Probing in OPD couldn't be done and was performed during surgery. Rest of the examinations were normal

Since this opening was at very atypical site for the common anomalies such as branchial and thyroglossal fistula, fistulogram was planned to see the extent of the tract. It showed considerable sized tract extending from submental region to the floor of mouth (Figure 1). Excision of the tract was planned

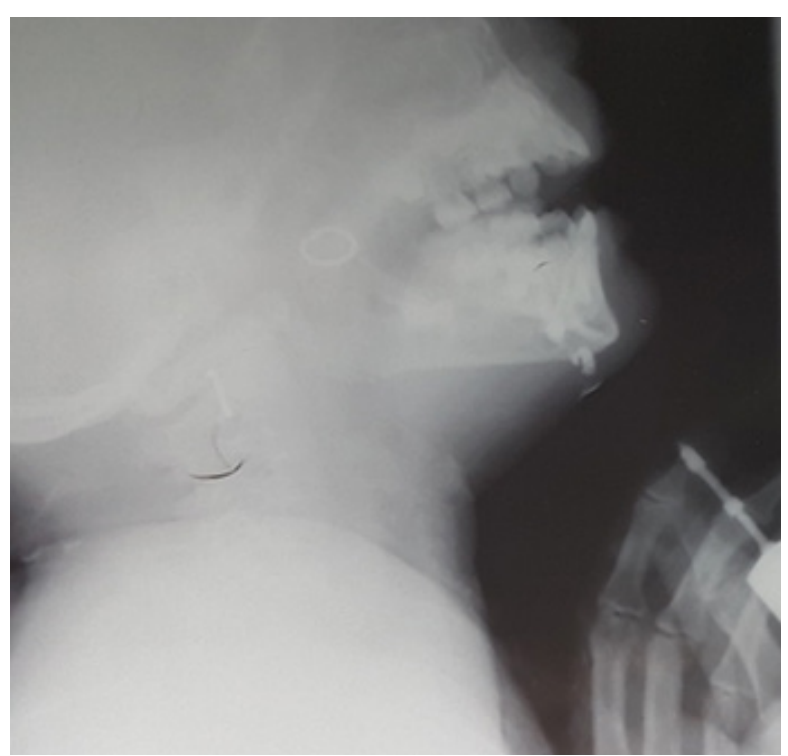

Figure 1. Sinogram of submental fistula 
under general anaesthesia.

The child was kept in supine position with neck in extension. Elliptical incision was given surrounding the opening and subplastysmal flaps were elevated. Tract was dissected from the surrounding soft tissue tracing it between anterior bellies of diagastric and above hyoglossus up to the base of tongue. The distal end of the tract was arising from the junction between anterior two third and posterior one third of the tongue. It was then clamped, ligated, cut and the sital stump was cauterized. The excised specimen was sent for histopathological examination and wound was closed in two layers.

The child was discharged on $4^{\text {th }}$ post-operative day and followed up at OPD after 10 days with histopathological report. Histopathological examination showed features of thryroglossal duct tract (Figure 2) which was lined with stratified squamous epithelium containing keratin debris. The child was again followed up after three months of surgery. The wound was completely healed with minimal scar, there were no complaints of swelling in and around the scar site or anywhere in the neck.

\section{DISCUSSION}

Thryoglossal duct cyst is one of the most common midline neck swellings presenting in paediatric population, although it can present at any age starting from birth. Its presentation is rare after 70 years of age and only 13 cases have been reported so far. ${ }^{2}$ It doesn't have any gender predilection.

Presentation may be as a cystic swelling or as a fistula following rupture of the infected cyst. Location may vary with thryohyoid region accounting for $60.9 \%$ cases followed by suprahyoid (24.1\%), suprasternal $(12.9 \%)$ and intralingual (2.1\%). ${ }^{1}$ Several rare presentations of thyroglossal cyst have been have reported such as giant neck swelling with stridor, ${ }^{3}$ thyroglossal cyst with intralaryngeal extension, thryoglossal cyst carcinoma ${ }^{4}$ and often with multiple tracts. ${ }^{5}$

Diagnosis is usually clinical, however ultrasonography is often required to see the status of the thyroid gland as in some cases the cyst may be the only tissue containing functioning thyroid tissue. FNAC aids in diagnosis in some confusing cases however it is not always necessary.

Treatment is usually surgical with removal of cyst or fistulous opening, tract tracing up to the foramen caecum including central portion of body of hyoid and core of tongue base muscle.

In our case the presentation was very atypical. The child presented with submental sinus with intermittent discharge for one year. Thyroglossal fistula was not considered initially as the diagnosis considering the atypical location of the sinus. Excision of the whole tract was done after tracing its

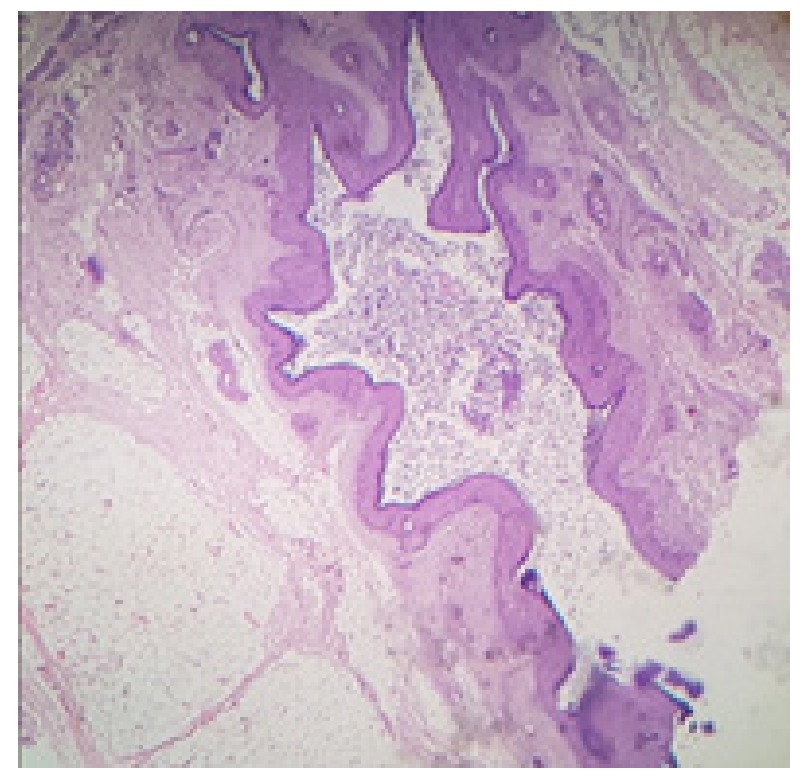

Figure 2. Histological slide of thryoglossal tract

distal origin up to the base of tongue. Since the tract was considerably higher up in relation to hyoid, we did not remove the central portion of body of hyoid. Diagnosis was only confirmed after histopathological examination. Although suprahyoid presentation of thyroglossal fistula is common, we could not find literatures mentioning the location of cyst of fistulous opening in the submental region.

\section{CONCLUSION}

Thyroglossal cyst being a developmental anomaly can present at any site extending from base of tongue to lower neck. Though atypical for presentation of any common sinuses or fistulas in neck e.g. thyroglossal fistula, branchial fistula, every fistulous tract must me meticulously followed up to its site of origin and should always be sent for histopathological examination after surgery.

\section{REFERENCES}

1. Filho FW, Costa FW, Turatti $E$, and Cavalcante RB. "Extensive thyroglossal duct cyst in 83-year-old patient," New York State Dental Journal, vol. 78, no. 3, pp. 39-41, 2012.

2. Maran AG. Benign diseases of the neck. In: Kerr AG, ed. ScottBrown's Otolaryngology. 6th ed. Vol. 5. Oxford: ButterworthHeinemann; 1997:1-4.

3. Venkatesan SK, Manoharan KS, Parida PK, Alexander A, and Gopalakrishnan S. Stridor in an Elderly Woman: An Unusual Presentation of a Giant Thyroglossal Cyst, Case Reports in Otolaryngology, vol. 2013, Article ID 340814, 3 pages, 2013.

4. Barton FB, Jane LW, Thomas LK. The CT appearance of thyroglossal duct carcinoma. Am J Neuroradiol 2000;21:1547-1550.

5. Das JR, Biswas D, Manickam A (2016) Thyroglossal Fistula Presented with Multiple Tracts -A Case Report. Otolaryngol (Sunnyvale) 6:221. 